\title{
HISTORICCIDAD DE LOS «MIRACULOS ROMANÇADOS» DE PEDRO MARÍN (1232-1293): EL TERRITORIO Y LA ESCLAVITUD GRANADINOS
}

\author{
SUMARIO \\ I. Historiografía e historicidad de los manuscritos. - II. Territorio y socie- \\ dad granadinos. 1. Vegetación, agricultura y alimentación. 2. El trabajo. 3. La \\ venta en el mercado de esclavos. - Apéndice documental.
}

El Monasterio de Silos fue fundado en el siglo XII según una serie de tradiciones que se vienen aceptando secularmente y que Pérez de Urbel concretó con mayor precisión en el reinado de Recaredo '. Su situación en el fondo del valle de Tabladillo favoreció en sus orígenes una primitiva estructuración en colonias dispersas de monjes eremitas que fácilmente podían observar unas mínimas reglas de vida en común, de una manera muy similar a la descrita por Orlandis en las comunidades monásticas de El Bierzo ${ }^{2}$. Esta inicial dispersión monástica, que puede calificarse de colonización del valle de Tabladillo por los monjes, tuvo un centro de aglutinación en los tiempos inmediatamente posteriores a la invasión musulmana, en el entonces llamado monasterio de San Juan. Posteriormente, con la regla benedictina completamente asimilada ya, Fernán González lo reorganizó en 954 dándole el nombre de San Sebastián de Silos, sobre la base demográfica de dos villas ya muy bien definidas, Santiago de Silos y San Juan de Silos ".

Bajo la advocación de San Sebastián continuó el monasterio su evolución hasta que la figura de Santo Domingo, que fue su abad entre los años 1040 y 1073, le imprimió un nuevo rumbo al introducir en él la reforma cluniacense; su abandono del priorato del monasterio de San Millán de la Cogolla, por su tan

1 Fray Justo PÉReZ DE URBel, Los monjes españoles en la Edad Media, Ediciones Ancla 1934, I, p. 515.

2 J. ORLANDIS, Estudios sobre instituciones monásticas medievales, EUNSA 1971, pp. 71 y sig.

3 A. RepreSA, El "burgo" de Santo Domingo de Silos. De las "vilas" a la "villa» de Silos, Homenaje a Fray Justo Pérez de Urbel, OSB, «Studia Silensia» III, Abadía de Silos, 1976, I. J. PÉREZ DE URBEL, Los monjes..., II, pp. 293 y 386. 
conocido enfrentamiento con el rey García III de Navarra, fue el origen de su llegada a Castilla donde pudo realizar lo que había intentado sin éxito en San Millán, potenciar el crecimiento de la abadía de Silos con el respaldo de Fernando $\mathrm{I}^{4}$, permanente protector de la Iglesia a lo largo de su reinado (1032-1065), con el que coincide ampliamente la vida de Santo Domingo de Silos. Tres años después de la muerte del santo, en un documento de 1076, ya se había producido el cambio de advocación del monasterio ' y empezaban a desarrollarse las tradiciones hagiográficas referentes a él; su tumba acabó convirtiéndose, como la de tantos otros santos en la Europa de la época ${ }^{6}$, en un centro de perenigración al que llegaban los fieles portando ofrendas como señal del reconocimiento, en el caso de Silos los instrumentos de tortura y las cadenas de la cautividad.

Ya a finales del siglo XIII el monje de Silos Pedro Marín hizo una relación de los «miraculos romançados» de Santo Domingo comprendida entre los años 1232 y 1293; sin afirmar en ningún caso que la relación fuese exhaustiva, sí puede considerarse que la integran aquellos relatos de peregrinos que más llamaron su atención por las dificultades salvadas por los protagonistas; son éstos los relatos escogidos de una mínima parte de los doce mil cautivos que, según la tradición, pasaron por Silos a testimoniar al santo su gratitud por haberles posibilitado la fuga de territorio granadino, al marcarles el camino e impulsarlos a lanzarse a una arriesgada huida con la aparición de su figura o el sonido de su voz.

Del monje autor no hay más referencia que su presencia autobiográfica en el milagro número cuatro, que narra la estancia de Alfonso X en Silos en 1255, así como su presencia testifical en el milagro número noventa y dos; otra noticia de 1293, año en el que se cierran los relatos de los peregrinos, corresponde a un documento en el que aparecía su firma como mayordomo o procurador del monasterio'.

4 J. PÉREZ DE URBel, Los monjes... II, p. 434. H. GRASSOTTI, La iglesia y el Estado en León y Castilla de Tamarón a Zamora (1037-1072), «Estudios Medievales Españoles», Fundación Universitaria Española, 1981.

s A. Linage CONDE, Los origenes del monacato benedictino en la Peninsula Ibérica, Centro de Estudios e Investigación San Isidoro, CSIC, León 1973, II, pp. 617 y sig.

6 E-R. LABANDE, Spiritualité et vie litteraire de l'Occident, $X^{\prime}-X I V$, Variorum Reprints, London 1974, p. 285. A. VAUCHEZ, La spiritualité du moyen age occidental. VIII-XII siècles, Presses Universitaires de France 1975 y La Sainteté en Occident aux derniers siècles du moyen age. D'après les procès de canonisation et les documents bagiographiques, École Française de Rome, Palais Farnèse, 1981.

1 Fray Alonso ANDRÉs, Notable Manuscrito de los tres primeros hagiógrafos de Santo Domingo de Silos (Siglos XIII-XIV), "Boletín de la Academia de la Lengua», 1917, Cuaderno XVII, pp. 172 a 194, y XIX, pp. 445 a 458. 


\section{HISTORIOGRAFÍA E HISTORICIDAD DE LOS MANUSCRITOS}

Algo más conocida que el autor es su obra, aunque no lo es tanto como merece su gran valor historiográfico. En 1942 José Maria de Cossío dedicaba un pormenorizado artículo a la vida de los cautivos cristianos en territorio granadino durante el siglo XIII ${ }^{8}$, documentado en el texto de Pedro Marín; progresivamente, Cossío analizó las circunstancias bélicas de la cautividad de gentes avecindadas en las tierras castellanas próximas a la frontera con el reino de Granada, su apresamiento y conducción a distintos puntos del reino donde trabajaban hasta el momento de su venta; hizo un examen muy detallado de la tipología de las cárceles y los sufrimientos que padecieron para obligarlos a realizar el trabajo asignado o gestionar su rescate y terminó por examinar las condiciones en las que se producían las fugas y la vuelta a sus puntos de origen, a veces al cabo de muchos años desde que fueron capturados, en una época de inestabilidad fronteriza correspondiente a los reinados de Fernando III, Alfonso $\mathrm{X}$ y Sancho IV, que se vio acentuada por la llegada de los refuerzos africanos merinies a partir de la conquista de Niebla de 1262.

El trabajo de Cossío marcó un hito en los estudios que hasta entonces se habían hecho de "Los milagros», porque fue el primer autor que utilizó su riquísimo contenido de datos históricos totalmente verídicos para obtener de ellos unas conclusiones sobre el fenómeno social de la esclavitud en la historia peninsular del siglo XIII. Cossío reclamaba la necesidad de hacer una edición, como después lo han seguido pidiendo otros autores en función del valor

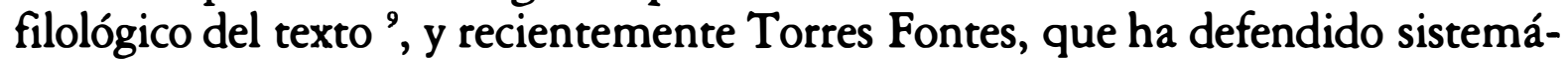
ticamente la historicidad de los relatos recogidos por Pedro Marín ${ }^{10}$.

El texto del monje de Silos Pedro Marín se conserva actualmente en dos manuscritos, copias ambas del original hoy desaparecido: el primero está incluido en el códice MS. núm. 12 que se conserva en el monasterio de Silos en el que además de recoger las copias de Vidas de Santo Domingo de Grimaldo, escrita en latín en los finales del siglo XI, y la de Gonzalo de Berceo en verso que se inspira en la anterior; este manuscrito apareció en 1915 en el pueblo burgalés de Carazo después de que sufriera las consecuencias de dispersión de la desamortización de Mendizabal, de 1835.

${ }^{8}$ J. M." Cossío, Cautivos de moros en el siglo XIII, "Al-Andalus» VII, 1942, pp. 49-

9 I. FERNÁNDEZ DE LA CUESTA, Notas paleográficas al Antifonario Silense del Museo Británico (MS. ADD. 30.850), Homenaje a Fray Justo Pérez de Urbel, OSB, «Studia Silensia» III..., 1.

${ }^{10} \mathrm{~J}$. TORRES FONTES, Repartimiento de Lorca, Ayuntamiento de Lorca-Academia Alfonso X El Sabio de Murcia, 1977, y La cautividad en la frontera granadina (1275-1285), "Cádiz en el siglo XIII", Cádiz, 1983. 
La otra copia conservada del texto de Pedro Marín está incluida en el manuscrito núm. 5 de la Real Academia Española de la Lengua, en el que también se incluyen los textos de Grimaldo y de Berceo.

Un año después de la afortunada aparición del primero de los dos manuscritos, fray Alfonso Andrés publicó un estudio crítico del mismo, así como de las fuentes documentales hasta entonces conocidas de la vida de Santo Domingo de Silos según los tres autores en el manuscrito contenidos ", cuya única edición completa hasta aquel momento es la que hizo en 1736 el entonces abad del monasterio, padre Sebastián de Vergara ${ }^{12}$, sobre la cual trabajó José M." de Cossío.

Entre los autores anteriores a Vergara, todos ellos monjes de Silos, que abordaron la vida de Santo Domingo inspirándose de diversa manera en Grimaldo, Berceo y Pedro Marín, es importante la obra de Ruiz de Montiano escrita entre 1613 y 1675 , que afirma categóricamente haber utilizado los manuscritos originales de Grimaldo y Pedro Marín ${ }^{13}$.

Ya en el siglo XIX, cuando los fondos de la biblioteca del monasterio habían sufrido el proceso de dispersión que siguió al decreto de disolución de la comunidad y su abandono por los monjes el 17 de noviembre de 1835 , don Marius Ferotin estuvo trabajando en el todavía bastante completo archivo entre 1880 y $1890^{14}$; como fruto de su trabajo publicó en París en 1897 una historia de la abadía y una colección de cartas que han contribuido a conservar con exactitud datos y noticias referentes a los textos de los tres autores medievales y al contexto histórico en el que se desarrolló el monasterio.

El manuscrito conservado en el monasterio tiene la falta parcial de los tres folios finales, desde por lo menos los tiempos anteriores a que lo utilizara Vergara, quien ya acusó este hecho, aunque siempre estuvo convencido de que era el texto original de Pedro Marín y no una copia, como también lo es el

$"$ A. ANDRÉs, Notable manuscrito...

12 S. de Vergara, Vida y milagros del Thaumaturgo español Moysés segundo, Redemptor de Cautivos, abogado de los felices partos, Santo Domingo Manso, Abad benedictino, reparador del Real Monasterio de Silos, Herederos de Francisco del Hierro, Madrid, 1736.

13 G. Ruíz DE MONTIANO, Historia milagrosa de Santo Domingo de Silos, abad de la orden de San Benito: que contiene no solo las maravillas desde Santo en vida y muerte y los antiguos sucesos de su real monasterior: $y$ de sus Prioratos y filiaciones, Archivo de Silos, manuscrito 21.

14 Marius, FÉrotin, Histoire de l'Abbayé de Silos par D. Marius Férotin. Benedictin de Solesmes, y Recueil des chartes de l'abbayé de Silos, Ernest Leroux Éditeur, París, MDCCC XCVII. Es la fuente básica utilizada para tratar el tema de la cautividad en Granada por autores contemporáneos como R. ARIÉ, España Musulmana (siglos VIII-XV), Historia de España dirigida por M. TUÑóN DE LARA, Labor 1982, III, y El reino nasrí en la época de Alfonso X, "Alfonso X y su época», Revista de Occidente, Extraordinario XI, núm. 43, 1984. 
contenido en el manuscrito de la Academia de la Lengua. Existió una tercera copia utilizada como las anteriores por Vergara porque el original ya había desaparecido por entonces; estuvo contenida en el códice $\mathrm{H}-18$ que se conserva en la Real Academia de la Historia, titulado en el índice de la Colección Salazar y Castro "Historia de la Vida y milagros de Santo Domingo de Silos, por fray Gonzalo de Berceo, monge Benito, por los años de mil i ciento. En verso castellano de arte maior». De esta copia sólo se conoce el texto del relato número noventa y dos ${ }^{15}$, incluido en el folio 18 a continuación del texto de Berceo con una nota marginal que alude a su pertenencia a los «milagros romançados que estan al principio»; falta esta parte inicial del manuscrito donde se recogía el conjunto de la obra de Pedro Marín.

Ya el padre Andrés hizo un examen de las características y diferencias de estos códices, que actualmente se pueden complementar con algunas adiciones. Consideró certeramente como más antigua la copia del monasterio de Silos, basándose en los estudios comparativos de Fitz-Gerald ${ }^{16}$, quien llegó a la conclusión de que las semejanzas existentes entre el manuscrito de Silos y el complemento de la Academia de la Historia se deben a que éste se hizo en el siglo XIV copiando directamente del anterior, que a su vez había sido copia del original hecha en el mismo siglo XIII, y por tanto prácticamente coetánea.

Hay otro dato incluido en ambos manuscritos que puede contribuir a valorar la mayor antigüedad de la copia de Silos y es la concesión de la marzadga al monasterio por Alfonso X en 1256 que narra el relato número 4 del manuscrito de Silos, impuesto que en la copia de la Academia de la Lengua se recoge como martiniega. Lomax ha demostrado que "los miraculos» de Pedro Marín sirvieron de fuente a una crónica posterior que responde el encabezamiento de «Relación de las cosas notables acaecidas en tiempo del rey don Alfonso e de su muerte...», sobre todo en los relatos de Pedro Marín número cuatro y veinte y cuatro que describen la estancia del Rey en el monasterio en 1256 y el estremecimiento que demostró a los presnetes en 1283 la autenticidad de la tumba de Santo Domingo, de tal modo que, según esta relación establecida, la aportación de «los miraculos» al mejor conocimiento histórico y hagiográfico de la abadía es incuestionable.

«El autor de esta crónica quiere ensalzar los derechos y el prestigio del monasterio de Silos, y hasta que se encuentre otra evidencia, parece lógico considerar que era monje de este cenobion, y escribiendo en la segunda mitad del siglo XIV, en la época en que estaban haciéndose las copias posteriores de

is Apéndice documental.

16 J. Fitz-GerAlD, La vida de Santo Domingo por Gonzalo de Berceo, París, 1904, y A. ANDRÉs, Notable manuscrito..., p. 191. 
«los miraculos», es lógico pensar que fue el original de Pedro Marín lo que el autor de la "Relación» utilizó para su trabajo y así lo admite Lomax ${ }^{17}$.

El tributo del manuscrito de la Academia de la Lengua concretado como martiniega, es aceptado así por Lomax al utilizar a Vergara que lo trasmitió como tal, porque evidentemente martiniega era en el siglo XVIII cuando él escribía; sin embargo es marzadga en la «Relación...» por Lomax comentada que sigue la tradición del manuscrito conservado en Silos, más antiguo que el anterior y casi contemporáneo del propio Pedro Marín, con quien este copista debió de coincidir algún tiempo en el monasterio. El desconocido autor de la «Relación...» consultó el original de Pedro Marín en el que constaba como marzadga.

Es cierto que la «Relación...» tiene errores de copista patentizados por Lomax, entre los que no incluye la marzadga-martiniega, porque en este caso no lo hay a pesar de la aparente contradicción existente; la clave para la solución del enigma la proporciona Ballesteros Beretta, quién en su tiempo también corrigió algunos de los errores, cronológicos siempre, cometidos por el copista del manuscrito conservado en Silos, en el relato de la estancia de Alfonso X en el monasterio en noviembre de 1255 .

Ballesteros negó la posibilidad de que la llegada real se produjese el lunes cinco de aquel mes, porque ese día fue viernes y el Rey estaba en Burgos en aquella fecha; tampoco 1255 fue el año de la muerte de don Diego López de Haro, como afirma el manuscrito, sino uno posterior, por lo que el autor, que por lo demás valora históricamente el relato porque «...respira veracidad...», sugiere como posible llegada de Alfonso X a Silos la del 12 de noviembre. A pesar de estos errores, Ballesteros aceptó todo el conjunto de la narración y consideró a Pedro Marín como un testigo presencial de los hechos que describió y que por tanto conocía muy bien ${ }^{18}$. Se equivocó en algunas fechas pero no en el contenido de los relatos.

El propio Ballesteros había recogido anteriormente en el itinerario real, de forma indirecta pero muy valiosa, la historicidad del privilegio de Alfonso X otorgando al monasterio de Silos la marzadga, que tal como dice Pedro Marín estaba fechado en Calatañazor el 19 de febrero de $1256^{19}$ :

a) Ballesteros constató la existencia del impuesto en su forma de martiniega a través de fray Juan de Castro ${ }^{20}$, otro monje historiador de Silos del siglo

17 D.W. Lomax, Una crónica inédita de Silos, «Homenaje a Fray Justo Pérez de Urbel, OSB»..., 1, PP. 325 Y 331.

18 A. Ballesteros BeretTA, Alfonso X El Sabio, Ediciones El Albir S.A., 1984, pp. 123 a 128, y El itinerario de Alfonso El Sabio, Tipografía de Archivos, 1935, pp. 139 y 143.

19 A. BALleSTEROS BERETTA, El itinerario..., p. 153.

20) J. de CASTRO, El glorioso thaumaturgo español, redentor de cautivos, Santo Domingo de 
XVII, cuya obra es un extracto de los tres autores base, Grimaldo, Berceo y Pedro Marín, realizada en opinión de Fitz-Gerald en lo que a «los miraculos» se refiere, a partir de un códice hoy incompleto de la Academia de la Historia del siglo XIV, el tiempo en que la forma del impuesto era ya martiniega.

b) En segundo lugar, Ballesteros tomó de Ferotin la concesión en el mismo lugar y fecha anteriores, de 375 maravedís de marzadga que el Rey recibía anualmente de los habitantes de Silos; dadas las características de rigor de la obra de Ferotin, que empleó no solamente los manuscritos de Pedro Marín ya comentados, sino también toda la documentación del archivo monacal que contribuyese a recoger la historia de la abadía además de la vida del santo titular, esta confirmación de la concesión de la marzadga concretada en su cantidad exacta está tomada del documento real original hoy desaparecido $y$, con palabras de Ballesteros, «...allí está la explicación de la merced según el texto de Pedro Marín».

Efectivamente, tras una concesión inicial de Fernando III al monasterio de 1219, de la cuarta parte de los pechos de marzo consistentes en dos sueldos anuales que los vecinos de Silos pagaban al Rey como censos de sus casas, Alfonso X en 1265 otorgaba toda la marzadga por un valor de 375 maravedís y como tal marzadga la tomaron Pedro Marín y el copista más antiguo que fue el autor del monasterio de Silos; posteriormente y en fecha imprecisa se empezó a cobrar en San Martín, como los yantares, que en 1260 ya se cobraban en esa festividad que se adaptaba mejor a la realidad económica del valle de Tabladillo, decidiéndose su permuta cronológica por ser algo beneficioso; como martiniega se cobraría ya en el siglo XIV y así la recogieron los copistas posteriores al autor de la copia de Silos, entre ellos el autor del códice de la Real Academia de la Lengua.

No hay error como contribuyó a difundir Vergara al tachar marzadga y anotar al margen del códice de Silos martiniega, sino una adaptación a realidades mejor conocidas en tiempos nuevos de un códice respecto al otro más antiguo.

«Los miraculos» están comprendidos en el manuscrito de Silos entre los folios 23 y 87 de la numeración empezado por Gonzalo de Berceo, que a su vez sustituye a la romana coetánea del manuscrito que enumeraba del folio I al LXV todo el texto de Pedro Marín de forma independiente. En el manuscrito de la Academia de la Lengua están comprendidos entre los folios 1 y 38 del códice, que también tiene un lenguaje bastante más evolucionado que el de Silos.

Sin entrar en planteamientos propios de un estudio filológico, que no son objeto de este trabajo, se observan unas tendencias en el manuscrito de la

Silos. Su vida, virtudes y milagros; noticia del real monasterio de Silos y sus prioratos, Melchor Álvares, Madrid, 1688, p. 244. 
Academia de la Lengua a la desaparición de las consonantes dobles, tanto las del comienzo de palabra como las intermedias, en contraposición al paso de la $\mathrm{L}$ sencilla a la doble; la sustitución de la Y vocal por la I latina, la mayor aproximación a la exactitud actual en el empleo de $\mathrm{B}$ y V, sustitución en muchos casos de la $\mathrm{T}$ final por la $\mathrm{D}$ y de la conjunción et por e y, en general, más desarrollo de algunos párrafos, excepto en aquéllos en los que el copista se confundió y dejó algunas palabras olvidadas. Hay en el lenguaje del manuscrito de Silos una sensación de inmediatez cronológica en algunas narraciones, que se palpa en la utilización del «dizen», mientras que en el de la Academia de la Lengua se sustituye por un "deçian» que nos aleja en el relato del tiempo, tal como se ve perfectamente en el milagro número treinta y ocho.

Vergara trabajó su edición de «los miraculos» de Pedro Marín sobre los dos manuscritos de Silos y Academia de la Lengua y otro más, deducible de sus referencias escritas a un tercer códice, como observó el padre Andrés y que en su opinión debió ser el que completaba el códice de la Real Academia de la Historia. Vergara buscó editar la mayor cantidad de texto posible complementando unos manuscritos con otros, aunque desde luego la base la tuvo permanentemente en el manuscrito hoy conservado en Silos, que contiene gran cantidad de anotaciones que permiten seguir la huella concienzuda del trabajo de un estudioso como él; acudió a la copia de la Academia de la Lengua cuando el texto base de Silos estaba borrado, como ocurre en el milagro número cinco, y no lo entendía fácilmente, después de haber subrayado aquello en lo que dudaba, de haber repasado con su mano letras descoloridas y de haber marcado con una cruz faltas que observaba, sobre todo ésto último, en la copia de la Academia de la Lengua.

Es interesante observar las anotaciones que hizo en el texto de Silos para regularizar la puntuación, añadiendo signos de interrogación que el manuscrito no tenía originariamente y rayas verticales para introducir separaciones en los larguísimos párrafos del texto, aunque lo más interesante no es este trabajo de corrección en abstracto, sino el hecho de que es irregular y solo aparece en partes del texto, como el milagro número veinte y tres, donde siendo muy necesario no hay señal alguna en el manuscrito y sin embargo la edición tiene toda la puntación regularizada con arreglo a los criterios del resto de los relatos. Vergara debió tener algún fraile ayudante durante algún periodo del tiempo que tardó en preparar la obra y que a ello se deben las diferencias en la cantidad de anotaciones de los distintos folios del manuscrito de Silos, cuando la obra impresa tiene una gran constancia en los criterios aplicados. Publicó el texto íntegro excepto los milagros cincuenta y dos y ochenta y dos porque no hacen referencia a cautivos, que es el tema central de toda la obra, al cual se ciñó Vergara escrupulosamente.

Recientemente se ha publicado una nueva edición de los «Miraculos 
romançados» preparada por K.H. Anton ${ }^{21}$, que deja muchos puntos en el aire por la circunstancia de no haber utilizado el manuscrito de la Real Academia de la Historia, que a pesar de no conservar más que una mínima parte del texto explícito de Pedro Marín, resulta de uso historiográfico imprescindible.

\section{TERRITORIO Y SOCIEDAD GRANADINOS}

Pedro Marín, un monje que no habría estado nunca en las tierras de la frontera y menos aún en el interior del reino granadino, proporcionó una visión de su paisaje y la vida de los cautivos en su territorio de absoluta coherencia, obtenida a través de la información oral que le proporcionaban los peregrinos que llegaban al monasterio de Silos a agradecer su libertad a Santo Domingo.

\section{Vegetación, agricultura y alimentación}

Las escuetas descripciones paisajístas de los «miráculos» revelan un medio físico fundamentalmente xeromorfo, en el que la vegetación climática resultante era relativamente variada.

Pedro Marín habla de «hierbas» con insistencia, cuando los cautivos que huían de su prisión durante días y noches sin tregua tenían que esconderse entre ellas y, al mismo tiempo, alimentarse de ellas $[27,41,67,68,72]^{22}$; hierbas que se daban con profusión, entre ellas muchas gramíneas silvestres como el esparto, que no solamente era la única alimentación de los fugados durante muchos días de precipitada andadura, sino que también se utilizaban en tiempo de cautiverio para hacer con ellas el «pan de grama buelto con rayzes de gramones» [43] que tuvo como única alimentación Larios de Burgos en su prisión de Alcalá de Abenzaide. El esparto ocupaba ya amplias extensiones de territorio a altitudes sobre el nivel del mar muy diferentes y con climatología muy matizada, como la de rasgos continentales de las cuencas intrabéticas o las subtropicales costeras mediterráneas, tal como muestran los testimonios de Aparicio de Plasencia que estuvo cautivo en Málaga [26], Rodrigo de Siete Iglesias que lo estuvo en Guadix [32] y Ramiro de Matrera que lo sufrió en Ronda [47]. Estas «hierbas» formaban parte del sotobosque mediterráneo propio de los encinares, a veces a considerables altitudes medias.

Todavía la encina era el árbol predominante en las llanuras andaluzas y en

${ }^{21}$ K. H. ANTON, Los «Miráculos romançados» de Pero Marín. Edición crítica, introducción e indices, «Studia Silensia» XIV, Abadía de Silos, 1988.

${ }^{22}$ Los números entre corchetes hacen referencia a la numeración de los relatos correspondientes en la edición de K. H. ANTON. 
las tierras no muy altas, en formaciones suficientemente compactas como para que Aparicio de Plasencia, que había dado muerte con un azadón a su guardián Brahem cerca de Málaga, buscase un escondite en un «carrascal» desde el que, el día siguiente tras la aparición de Santo Domingo, inició el cruce de las cordilleras en dirección a las llanuras del interior y en definitiva hacía la frontera [26].

La vegetación arbustiva degradada, que con el nombre de garriga caracteriza el paisaje de extensas comarcas de suelos calcáreos o margosos del interior, está perfectamente descrita por Pedro Marín en una escena cinegética de indudable realismo y belleza [44], en la que el cautivo Martín Domínguez, que había huido de su prisión en Ronda, tuvo que esconderse entre el matorral en el que los podencos de unos cazadores moros con halcones estuvieron a punto de descubrirlo y si no lo hicieron fue por el oportuno vuelo de una perdiz que distrajo su olfato en otra dirección y, entre las matas, siguió esca moteando más de cien cazadores que en domingo se dedicaban a la caza de conejos, liebres, perdices... Los acebuches u olivos silvestres eran la nota dominante en el camino de Écija a Córdoba en el que Miguel Pérez fue capturado [62].

En las llanuras costeras, plantas muy termófilas y xerófilas, como el palmito, constituían el elemento fundamental de la vegetación natural que Mari Pérez encontró en su huída del Portal de Jerez, antes de llegar al valle del río Salado [79]: como en tales ocasiones la vegetación ofrecía la posibilidad de un escondite oportuno y afortunado, pero el fraile Pedro Marín describe en cada huida el paisaje justo y las plantas concretas que corresponden a características edáficas y climatológicas diferenciadas con matices exactos.

En los suelos silíceos que son el elemento edáfico dominante en las estribaciones de Sierra Morena y extensas áreas de las Cordilleras Béticas, la jara constituía el tipo de vegetación que llenó los ojos de los fugados o los apresados: Simón Segura iba «...a ganar algo contra Granada...» con otros compañeros, cuando en el ataque a un innominado castillo fue apresado entre las jaras y conducido cautivo a Guadix [11] y Salvador de Sevilla fue igualmente apresado entre una jaras próximas a Utrera y conducido desde allí a Ronda [64]. La extensión de los jarales andaluces es la mayor de España y probablemente de todo el Mediterráneo ${ }^{23}$.

Junto a las orillas de los rios los cañaverales y juncos de considerable altura proporcionaron el medio de que Martín Domínguez se escondiese en su accidentada huida para evitar el peligro de que lo viesen dos moros que hicieron un alto en el camino para descansar y asearse: «...los moros legaron a la fuente, descalçaron sus pannos menores et lauaron sus naturas, et los pannos echaron-

23 J. Sermet, Andalucia, "Geografía de España y Portugal» dirigida por Manuel de TERÁN, Montaner y Simón 1967, IV, 3.` parte, p. 87. 
los a enxugar en los yuncos do el yacia, despues que fueron enxutos calçaronlos, et tomaron sus armas et fueron su via» [44].

Cuando describe estos paisajes Pedro Marín resalta con avidez la existencia de agua dulce en una fuente o un rio, en contraste con su carencia absoluta en la mayor parte de la región y, sobre todo, en contraste con las aguas estancadas y a veces salitrosas que caracterizan las Marismas del bajo Guadalquivir, elementos de contraste que, por otra parte, están más acentuados en el norte de África, en donde don Juan, un vecino de la aldea de Isso, próxima a Hellín, después de llevar seis días sin beber agua, «...fallo una fuent de bona agua dulce, et beuio dela tanto que non se podia mouer...» [55]; más adelante, de vuelta a la península, llegó a las proximidades del estrecho, atravesó sierras, cruzó caminos de monte entre grandes peñascales para teminar en «las Albueras de la sierra de Algezira», el valle del Guadalete y acabar en su larga andadura de cautivo en Veger. Montañas, valles fluviales, campos y bahías fueron recorridos por el cautivo y descritos por Pedro Marín con auténtica fidelidad e intuición que contrasta vivamente con las frías relaciones y descripciones toponímicas que constituyen la base geográfica del «Libro de la Montería» de Alfonso XI.

Aspectos importantes de la explotación económica de Granada quedan cabalmente descritos en los relatos de estos cautivos que llegaron hasta Silos, sobre todo los variados tipos de cultivos, que resultan muy notorios en el texto gracias a las minuciosa pormenorización de los relatos.

Los cereales.- Constituían la base de la agricultura andalusí a lo largo de todo su territorio, tanto en el secano como en el regadío, formando parte de un sistema agrario tratado por Torres Delgado y López de Coca ${ }^{24}$. El mayor número de las citas que a ellos hacen referencia se acumulan en los milagros que tuvieron lugar en parte de las actuales provincias de Córdoba, Granada y Jaén, es decir, en aquellas áreas máas continentalizadas o con mayores índices de aridez como es el caso de Almería, demostrándose con ello una adaptación del cultivo en función de sus más racionales exigencias, lo cual resulta un dato más a aportar a la confirmación de la ya sólida hipótesis de que la reconocida sabiduría de botánicos y agrónomos musulmanes saltó de la pura teoría a una práctica muy generalizada ${ }^{25}$.

${ }^{24}$ C. TORRES Delgado, El reino nazari de Granada (1232-1492). Aspectos socioeconómicos y fiscales, "Actas del II Coloquio de Historia Medieval Andaluza», Sevilla 1982. J.E. LÓPEZ DE COCA CASTAÑER, El reino de Granada, "Organización social del espacio en la España Medieval. La Corona de Castilla en los siglos VIII al XV», dirigido por J.A. GARCíA DE CORTÁzAR, Ariel, 1985, p. 201.

25 J. VERNET GINÉS, y J. SAMSÓ MOYA, Panorama de la ciencia andalusí en el siglo XI, "Actas de las Jornadas de Cultura Árabe e Islámica (1978)», Instituto Hispanoárabe de Cultura, 1981. 
Cultivos de secano en régimen extensivo de año y vez, en los que las alquerías constituían la forma básica, tanto de poblamiento como de explotación económica, siendo en ellas la mano de obra cautiva un elemento fundamental del trabajo agrícola de estas grandes propiedades. Sancho de Úbeda estuvo arando durante año y medio en la alquería que, en término de Guadix, tenía un primo del arraiz de dicha plaza, Alí [89] y como él Ruy Pérez, cautivo en otra alquería granadina de propiedad real [38], y muchos otros que más adelante se irán comentando.

Pero hay que señalar que el volumen anual de los cereales obtenidos no cubría más que muy raramente las exigencias de la población granadina, porque el territorio, en su mayor parte montañoso, dificultaba de modo determinante su cultivo. El gran granero de la llanura del Gualdalquivir ya se había perdido y no es de extrañar que los cautivos en estas condiciones pasasen hambre y a ellos se destinase el pan de ínfima calidad ${ }^{26}$.

La escanda, especie de trigo con una paja bastante dura que difícilmente se separa del grano, se cultivaba en su variedad roja y constituía un alimento fundamental de los cautivos, en contraposición a los trigos de mejor calidad que prácticamente éstos casi nunca llegaban a probar en su alimentación ordinaria. El pan elaborado con «escandia» constituía la base de la alimentación de muchos de ellos, que se lamentaban, ya narrando sus peripecias en Silos, de la escasa cantidad que recibían y, además, de su ínfima calidad: un poco de este pan recibieron diariamente García de Úbeda en su cautiverio de Almería [67], Martín de Cabra que estuvo preso en Rute [71], Benito de Aguilar y don Miguel de Cetina, que lo sufrieron en Málaga [72 y 77], y Benito de Barajas que estuvo en Vera y, además de parecerle una alimentación precaria, la calificaba de áspera [75]. A Miguel Pérez, en Guadix le proporcionaban una onza diaria de este pan, 287 gr. [48], y en la misma localidad a Domingo Muñoz una cantidad algo mayor, una libra, 460 gr. [68], lo cual suponía una mejor suerte relativa respecto a otros cautivos. Posiblemente el mejor parado de todos los testimonios registrados por Pedro Marín fue Ramón de Mula, que en Purchena comía diariamente dos panes, pero se quejaba «que semejaba arena» [41]

Solamente Nicolás de Alcaraz que diariamente molía cebada para la alimentación de sus compañeros cautivos con él en Vera, participó alguna vez del pan de trigo denominado por él simplemente pan [30]. Su relato coloca a la cebada a la altura de los cereales panificables de baja calidad, pero de consumo relativamente extendido de Martín de Játiva, que se alimentó de pan de cebada en Guadix al cabo de tres dias de no consumir más que agua [29] y Juan de

${ }^{26}$ El hambre ha sido valorada como el primero de los sufrimientos físicos que padecían los cautivos por M. GONZALEZ JIMÉNEZ, Esclavos andaluces en el Reino de Granada, "Actas del III Coloquio de Historia de Andalucía», Diputación Provincial de Jaén, p. 336. 
Segura que lo consumió en Baza [69]. Siempre en comarcas donde la aridez está más acentuada, de tal modo que cuando algunos de ellos pasaron a los mercados de esclavos africanos, la cebada común o en su modalidad de hordio, seguía constituyendo la base de su precaria alimentación, tal como luego testificó en Silos Juan "Buhón», en contraposición al trigo que integraba la base de la alimentación de los naturales a través del kuskusû: «et fazian los Moros cada dia de la farina conducho que auia nombre cozcucho» [55].

Muy extendido debió de estar también el cultivo del panizo en sus dos variedades fundamentales, de grano amarillo-rojizo que es la propiamente considerada panizo y la de grano negro o zahina; el consumo del primero está testimoniado fundamentalmente por los cautivos que estuvieron en Granada y Almería; sin bien algunos consideraban que se les había entregado en muy poca cantidad, como fue el caso de Pedro de Tobarra [57], el de Yoannes Domingo que estuvo preso en Gergal donde lo consumió de panizo y escandía, o Gil Pérez y otros compañeros granadinos que recibían «...mui poco que non se fartauan...", los demás que tuvieron una alimentación a base de pan de panizo recibieron sistemáticamente libra y media diaria, tanto en la ciudad de Granada, los casos de Esteban de Montoro [36], Ruy Pérez de Jaén, que fue cautivo real [38], Benito de Jaén [39], como en Vera donde habían estado Alfonso Pérez [33] o en Ronda donde estuvieron Salvador de Sevilla y tres cautivos más [64].

La exactitud de las cantidades que diariamente se les proporcionaban hace pensar que existiesen una especie de tasas en la alimentación de los esclavos granadinos, que partiendo de la carencia absoluta de pan de trigo, salvo que circunstancias extraordinarias que pasaban por que la benevolencia de los amos lo proporcionase, alcanzaba una escala en función de la calidad y estima del cereal: entre una onza y una libra cuando se trataba de pan de escanda y libra y media en el caso del panizo, cuyas características de ingestión eran más desagradables y de un valor nutritivo considerado inferior.

La zahina o panizo de grano negro no aparece documentada en el consumo de los cautivos que estuvieron en la ciudad de Granada, y sin embargo sí lo está con profusión, sola o mezclada con mijo y hordio en el resto de la geografía del reino granadino, constituyendo los panes más miserables que un ser humano pudiese comer. En mínimas cantidades no cuantificadas se consumía el pan de zahina en las zonas costeras o sus proximidades, en Algeciras [66]; lo recibieron Domingo de Merlán y Gonzalo de Soria, que se lamentaba al recordarlo ante el monje Pedro Marín de que era muy duro y parecía arena [53], y en el área de Málaga Miguel Pérez que estuvo en la ciudad [62] y «Bernabeio» y ocho compañeros cuyo cautiverio se centró en la fortaleza de Casarabonela [70].

Solamente mijo recibieron Fernán Pérez y varios otros cautivos en Ronda, «sennas presas de farina de mijo...» [74] y algunos otros testimonios hablan de 
diversas mezclas de los cereales considerados menos deseables, localizadas junto con el mijo también en Ronda, así el «ordio buelto con seyna que semeia mijo...» del que se alimentó Arias Pérez [40] y los «dos pannes chiquiellos de seyna buelto con mijo...» que le daban a Martín Domínguez [44].

La diversificación viene dada en primer lugar por el mejor tratamiento que devieron tener los cautivos granadinos en poder de señores acaudalados y en un centro urbano mejor abastecido que las demás ciudades del reino nazarita o que las fortalezas siempre más aisladas $\mathrm{y}$, en segundo lugar, por las costumbres locales que se perciben a través de las mezclas consumidas en Ronda, a pesar de que las descripciones son gráficas pero igualmente esquemáticas. Domingo Pérez de Salvatierra, cautivo en Los Alcandiles, fue uno de los que mejor describió el hecho a Pedro Marín al lamentarse de las ínfimas características del pan que comía: «...nol dauan a comer si non un poco de adobon que a el grano negro como de pimienta, que es el pan tal como carbones...» [81]

Árboles de secano.- Además de cereales, en el secano había profusión de higueras y almendros en extensiones considerables, como debía de ser el caso de la estructura agrícola que se vislumbra en el relato de Martín Domínguez, que en su huida de Ronda, antes de llegar a Osuna tras sus peripecias con los cazadores, sus halcones y podencos «...fallo almendros et comio daquellas muchas assi que se enbeddo...» y otro día después de pasar el valle de un rio, entró en tierras de labor que trabajaban dos moros con una yunta de bueyes «...et metiosse en una mata de figueras et los moros araron fata la tarde...» [44].

Alternancia de cereales con dos árboles tan adaptados a las condiciones climatológicas de la cuenca del Guadalquivir y las vertientes de la cordillera Penibética, en las que la higuera convivía y convive en proximidad con la vegetación natural en el testimonio de Aparicio de Plasencia: «...et el dia de Sant Miguel o estaua entre unas figueras uenol en coraçon que matasse un moro quel dizian Brahem quel guardaua, et tiro el azada et matol et fuyo a un carrascal et echosse a dormir..." [26]; bajo el sol de justicia de septiembre en las vertientes de Málaga, Aparicio de Plasencia soñó con la huida entre higueras y encinas.

El olivo pasa desapercibido en los relatos de estos cautivos; alguna vez citan el aceite, muy pocas o ninguna el árbol o cualquiera de las actividades que girasen en torno a su elaboración; la razón no puede ser su ausencia agrícola que está sobradamente comprobada que no era tal, sino el hecho de que no entraba en su propia alimentación, así como el que la molturación de la aceituna no debía de ser tan costosa como para estar encomendada a los cautivos, que siempre se veían obligados a realizar los trabajos más duros y más degradantes.

Horticultura.- Las viñas y los parrales constituían un cultivo ordinario en 
la vega granadina entremezclados con leguminosas y otras hortalizas, con tal frecuencia que su imagen documental recuerda la denominada "cultura promiscua» tan frecuente en la Italia meridional. Entre viñas y habas tuvo lugar la muerte de un renegado que vigilaba a Pascual Pérez y otros cautivos cuando se dirigían a su trabajo de labranza en la viña y el cual degollaron entre las matas de habas [27]; Gil Pérez y otros cautivos trabajaban cavando en un parral granadino [51], Pedro de Tobarra y sus compañeros de escapada en su huída por la puerta de Elvira se escondieron entre un plantel de habas [57], y Domingo Martínez y otros cautivos que con él habían estado en Granada habitualmente labraban y cavaban las viñas de su amo, entre las que tuvo lugar la captura de su guardián Mahomat, al que arrojaron a un pozo antes de huir [88].

Indudablemente vides y hortalizas se cultivaban en otras vegas andaluzas además de en la granadina, pero nunca con la intensidad y la extensión a que obligaba la presencia de la corte nazarita, el fundamental centro del consumo de calidad del reino. Aún en áreas muy peligrosas e inestables en las que las vegas podían sufrir las consecuencias de las acciones recíprocas de los fronteros castellanos en territorio granadino y de los zenetes africanos en territorio recientemente incorporado por Castilla, estos cultivos estaban implantados en torno a los núcleos de población más importantes; así es patente en el caso que demuestra el ataque del adalid de Granada, Abdalla, a las tierras cordobesas de la sierra de Priego, en el que cautivó a Martín de Cabra y otros varios «...entre las vinnas de Luçena.... [71]. También por entre las viñas norteafricanas próximas al mar, huyó el buhonero Juan llevando como valioso botín que le aseguraba la alimentación inmediata un «barquino» u odre lleno de leche [55].

Aprovechando la tradicción romana preexistente, los cultivos de regadío llegaron a alcanzar un altísimo grado de eficacia en el aprovechamiento del agua por medio de nuevas técnicas de origen mesopotámico, introducidas en la Península a través de Al-Andalus. El trabajo como motor muscular que hacía funcionar las norias fue una de las actividades de los cautivos, tal como ocurrió con García de Úbeda de Almería, que diariamente tenía que abastecer de agua los baños de su amo Hamet, sacándola de una profundidad de 130 sogas [67]. Las huertas regadas están perfectamente diferenciadas en los relatos de los cautivos de los secanos cultivados; el mismo García de Úbeda antes mencionado fue capturado en las proximidades de la huerta de Lorca, así calificada por él en su relato trasmitido por Pedro Marín, y Juan Martínez huyendo de los jinetes acampados en las proximidades de Algeciras recorrió un sendero «...entre la mar et unas huetas..." por el que consiguió entrar en Algeciras [45]; en ambos casos las huertas, una en territorio cristiano y otra en territorio granadino, estaban muy próximas a la frontera a pesar de los peligros permanentes que su situación entrañaba. 
La huerta proporcionaba unas condiciones de trabajo menos duras que el secano, por lo menos más sombra de árboles y más agua para refrescar, lo cual era valorable aunque el trabajo físico en ambas situaciones fuese semejante; ello explica que a Yoannes Domingo le dijese su amo Hamet el Aporchenin, un sábado del mes de abril, «...despues que fuste mio cativo nunquea salliste daqui a ninguna parte, anda comigo, yremos a la uerta, solazarnos emos un poco et uenirnos emos luego...» [65]; para un hombre que había estado nueve dias atado en una escalera, trabajar en la huerta en Gergal podía resultar auténtico solaz que terminó de la manera más liberadora para el cautivo, al sentir el impulso de Santo Domingo para matar al amo que cayó por el golpe de la azada sobre las cebollas que cavaba en esa huerta.

En muchos casos estas huertas eran pequeñas propiedades cercadas en el casco de las ciudades con caracter mixto de huerta y jardín, los reales como aquel de Almería en el que Benito de Barajas y Domingo Muñoz trabajaban, cercado por dos tapias aseguradas con puerta y llave, en el que apenas podían moverse a causa del frio y los miserables vestidos que llevaban, «...axunares de uil panno mui raidos...»; acurrucados en un rincon al sol recibieron la aparición de Santo Domingo [75]. Alí Alboazen, dueño de este real, acabó muerto por Domingo Muñoz aprovechando que su señor «...sacaua agua de una anoria et tyro un pico de fierro que tenia et dio al moro grant colpe en la cabeça et matol et dio con el dentro en el anoria» [68]. Los dos cautivos relataron por separado sus vivencias a Pedro Marín y las dos versiones son absolutamente complementarias.

\section{El trabajo}

El martes ocho de mayo de 1282 llegaba Gonzalo de Soria al monasterio de Silos y en el claustro del mismo, ante los ojos de los monjes acostumbrados a las penitencias corporales, enseñó su espalda martirizada por los azotes que recibió con una fuerte correa rematada con unos hierros, durante dos años y cuatro días en los que recibió entre 40 y más de 100 azotes diarios; Pedro Marín, que debía de estar presente entre los asombrados monjes, dice que «...teniallas tan cardenas de los açotes como color azul...» [53]. Era el trato habitual, matizado en cada caso, para obtener de los cautivos la máxima docilidad en el trabajo, unas condiciones más lucrativas en su rescate y en última instancia la conversión al islamismo.

Entre los trabajos realizados por estos hombres, los agrícolas y complementarios de la agricultura fueron la base de su utilización en el reino de Granada, a unas determinadas distancias de la línea de la frontera que por su inseguridad no permitía la actividad económica de forma continuada en sus proximidades ${ }^{27}$.

${ }^{27}$ J. TORRES FONTES, La cautividad de la frontera granadina... 
Actividades agricolas. - Los cautivos se dedicaban a cavar o remover la tierra con el azadón, a arar supliendo a las bestias de tiro o conduciéndolas solo en el mejor de los casos; de manera más globalizadora, Pedro Marín habla de la labranza, aunque a veces con el término de labrar se está refiriendo a los trabajos más diversos y no al concreto de trabajar y abrir la tierra.

La labranza con arado era un trabajo propio de las grandes haciendas, tanto las privadas como las pertenecientes al rey situadas más próximas a Granada; en ellas los obreros temporeros constituían una mano de obra habitual que por razones de economía monetaria eran sustituidos por cautivos cuando estos eran más abundantes después de las campañas militares. Pero de Tobarra le contaba a Pedro Marín que en la Puerta de Elvira de Granada, cuando él escapaba de la ciudad, había más de 600 moros «...que se alquilauan para ir a labrar...» [57]; evidentemente, en su afán de escapar no pudo detenerse a contarlos, pero la veracidad del texto es tal que la cifra es admisible como una globalidad aproximada que demuestra la importancia en la agricultura granadina de la población asalariada.

Los cautivos constituían en estas circunstancias una mano de obra mucho más barata, durante periodos de tiempo a veces muy prolongados, y repartidos por todo el territorio del reino nazarita: Domingo de Lista araba en Almería de sol a sol y de noche lo introducían en su profunda mazmorra de siete brazas de fondo [14]; en Vera, población muy pequeña, había 60 cautivos cuyo trabajo diario era la labranza y, dada la reducida extensión que podían tener sus cultivos y su condicionamiento a la altísima aridez de la comarca, sesenta cautivos trabajando debían suponer un porcentaje muy fuerte en el total de la mano de obra local [30].

En Ronda labró Arias Páez durante seis años [40] y Juan otros dos [42]; en Guadix Miguel Pérez estuvo haciendo el mismo trabajo tres años y medio [48]; Domingo Pérez aró y cavó en Los Alcandiles durante seis años, y Domingo Mínguez y ocho cautivos más labraron y cavaron viñas durante otros tres años en Granada [88]; Larios de Burgos en Almuñécar estuvo labrando un tiempo no concreto, pero largo [43], y en Algeciras otros doce cautivos hicieron lo propio [53] en unas condiciones tan generales a todos ellos que parece que no era un trabajo que se les asignase de manera circunstancial en tanto en el mercado se obtenía por ellos un precio elevado, por contrario, bien podía ser que trabajo y venta fuesen dos objetivos económicos complementarios; trabajaban porque se obtenía un beneficio muy considerable de ellos y se les vendía siempre en la coyuntura más oportuna, sin prisa que ocasionase dispendio.

El número de los que fueron a parar a las tierras del concreto término granadino fue muy elevado, sin duda el mayor a tenor de los abundantes testimonios transmitidos por Pedro Marín, y les estaban encomendadas tanto las tareas agrícolas como la reparación de las propias herramientas y la fabrica- 
ción de las abarcas, el calzado de la población rural. Trabajaban todos los días, incluso los domingos y días festivos como testificaban Juan Pérez con respecto al calendario cristiano, que no podían respetar él y sus cuatro compañeros que trabajaban en la misma hacienda que él [15].

Para algunos labrar no era cosa nueva, porque labrando estaba en la huerta de Lorca Alfonso Pérez cuando lo capturaron y en Granada continuó labrando con otros doce esclavizados como él [33], entre los que estaban Aparicio de Úbeda que fue capturado en una cabalgada [34], Esteban de Montoro [36] y Benito de Jaén [39], que lo fueron por Albohazán, el arrayaz de Andarax que los condujo a Granada, y allí se les dedicó a las tareas agrícolas con las que no todos ellos estaban familiarizados.

Sin embargo, la operación de cavar está mucho más repartida por todo el mapa del reino de Granada y más unida a las operaciones de cultivo de los regadíos en los que, por la pequeñez de la extensión y la más reducida de la parcelación, el uso del arado era menor: en un parral granadino cavaba Gil Pérez cuando Santo Domingo lo indujo a escapar y lo primero que sus compañeros y él abandonaron antes de ponerse en marcha fueron sus azadas [51]. En el real de su dueño Alí Alboazan, Domingo Muñoz cavaba durante su cautiverio en Almería, al mismo tiempo que construyó las tapias que lo circundaban [58], y en Baza Juan de Segura cavaba y segaba panizo y heno para el estiércol que necesitaban los animales [69].

También al mismo tiempo que cavaba en Purchena, Ramón de Mula hacía obras de albañilería que se complementaban [41], pudiéndose afirmar que prácticamente todos alternaban las tareas de la azada con otras ajenas a la explotación de la tierra, cavar y moler en el caso de Martín de Cabra, prisionero en Rute [71], o arar y cavar y otras labores, durante los seis años que Domingo Pérez estuvo en Los Alcandiles [81]. El campo tiene temporadas de mayor actividad y otras en las que el trabajo es menos intenso y permitía a los dueños utilizar a estos hombres de las más diversas maneras.

La molienda.- Sin duda era el trabajo más generalizado entre todos los cautivos que contaron sus experiencias a Pedro Marín al llegar al monasterio de Silos. Considerando los datos que ellos proporcionaron como un muestreo de la población esclava en Granada, resulta que la molienda fue el trabajo que la mayoria de ellos tuvo que realizar en alternancia con los agrícolas, artesanales o domésticos. Además de ser un trabajo necesario en todas las casas, era un trabajo muy duro, que se hacía sin interrupción «...et fazian los moler todo el dia...», decía Juan de Santallana en su experiencia norteafricana de Arcila [9]. Domingo de Lista lo alternaba con el arado en Almería [14] y Juan Pérez, en Granada, con la labranza [15].

Además catorce de los 24 relatos en los que la molienda era el trabajo 
exclusivo o compartido de los cautivos, tuvieron como factor común el hecho de que la molienda fuese manual, de lo que ellos dieron constancia porque significaba un agravante adicional a sus ya de por sí duras condiciones de vida; Arias de Zamora decía que en Ronda, donde él estuvo con otros tres cautivos, «...dauanles muchos açotes et otras muchas penas et molien el pan a braço, et porque non comiessen dello, metienles los frenos de fierro en las bocas apretados con candados...» [8], y Simón de Segura se lamentaba de que en Guadix lo compró un moro que «...fazial moler a braço et daual muchas penas...» [11].

En otro caso Juan Martínez tuvo que padecer en Algeciras, además de su separación física respecto a los demás esclavos de su amo Mahomat Anzadón, la obligación de tener que moler diariamente cantidades concretas de trigo, «...et fazianle moler cada dia trigo apeso...» [45]. El buhonero Juan, en Las Ferreiras, además de moler a brazo el trigo que se le encargaba, debía moler la cebada que constituía su diaria alimentación [55], y Arias Páez en Ronda molía un trigo endurecido que en su opinión tenía diez años [40].

Siempre se trataba de un trabajo muy duro y con mucha frecuencia controlado o a destajo, en la forma de cantidades diarias prefijadas a Domingo de Merlán, quien en Algeciras «...auia amoler cada dia una aroa de trigo o de seyna o de mijo, et auia de seruir los asetmanas...» [66], y a García de Córdoba, cautivo en Málaga, que diariamente molía cinco almudes de trigo a brazo [63]. A pesar de toda esta dureza en el trabajo y en el trato, podía sin embargo representar un alivio en una vida de inmovilidad con las gargantas, manos y pies atenazados por grilletes, cepos y todo tipo de instrumentos, de modo que en el relato de Domingo Ibáñez se aprecia el contraste entre las noches de dos años que pasó en Algeciras con la garganta en el cepo y los dias durante los que «... andaua por la villa moliendo a mano pora su Sennor et que gobernauasse...» [86].

Los productos que molían eran trigo, alheña, mijo, zaina o panizo negro y cebada, citados por el orden que establece la frecuencia de su anotación en el texto de Pedro Marín; los trigos de diversas calidades en primer lugar, porque constituían el alimento de sus amos; el mijo a continuación, en proporción similar a la de los dos tipos de panizo juntos, proporcionaba el indispensable sustento a los estratos de la población granadina más pobre o a sus cautivos y, en último lugar con mucha diferencia respecto a los demás cereales, la cebada que posiblemente sólo se empleara como alimentación humana en casos extremos de carencias locales o generales muy acentuadas. Junto a los diversos tipos de cereales la molienda de la alheña era la segunda variedad de este trabajo absolutamente generalizada en Granada, con poca diferencia respecto al trigo; se trataba de un arbusto oleáceo cuyas hojas previamente secas se trituraban y convertían en polvo que posteriormente se utilizaba para tintar. 
La construcción y otros trabajos.- Parece desprenderse de estos testimonios de los cautivos relatados en Silos que la construcción era el tercer tipo de actividad que se les asignaba en Granada, en sus diversas posibilidades de trabajo complementario y también como actividad única o compartida con las agrícolas, la molienda u otra cualquiera.

Además de cavar, tapiaban Ramón de Mula en Purchena [41] y Domingo Muñoz en Almería [68]; Gonzalo de Soria concretó más sus testimonios referentes a que en Algeciras «...fazianle tapiar en la Puebla que fazia Abiuçaf...» [53], en la que la actividad era intensa y los cautivos proporcionaron un trabajo intensivo, pues a Domingo Bono lo metieron en una «...alhondiga nueua et fazian le cada dia aserrar madera pora las casas nueuas que mando fazer Abyuçaf en la puebla nueua que a nombre el Almançora...» [46]; dos testimonios distintos acerca de esta construcción, que tenía mucho de fortificación, por la estratégica proximidad en que se encontraba respecto a la bahía utilizada como antepuerto de la propia «Algecira» tal como está documentada.

Las grandes campañas de conquista cristianas dieron lugar a una corriente emigratoria hacia el reino granadino que a su vez aumentó la densidad de población existente hasta entonces. Se hicieron necesarias no solamente unas fortificaciones eficaces, sino además los más elementales habitáculos para los nuevos habitantes, y en este sentido el testimonio de esa construcción se une al de Ruy Pérez, que durante cuatro años y medio fue cautivo del rey de Granada en una alquería en la que «...fazial labrar cada dia yesso en casas...» [38].

Otros cautivos en número no determinado estuvieron desempeñando oficios artesanales y solamente uno de ellos, Rodrigo de Lorca, fue pastor de «bestias» en Almería, ovejas que estaban guardadas, además de por el esclavo, por un gran perro «...mui brauo et uelador...» [49]. Los que trabajaron en la alfarería lo hicieron en la propia Granada, como Ibáñez Domingo, que estuvo 16 años haciendo redomas y tinajas [19], o en periodos de tiempo más reducidos, como los dos años y medio que Pedro de Tobarra además de moler alheña picó tierra para hacer ollas y terrazos [56].

En trabajos de fundición del hierro estuvieron ocupados en Guadix Rodrigo de Siete Iglesias [32] y en Ceuta Domingo Bono, que elaboraba «alhynde que tanto quier dezir en algarauia como azero muy fuerte con que calçan las espadas et las azagayas» [61]. Éstos fueron los dos casos únicos de artesanía metalúrgica que recogió Pedro Marín, porque las demás noticias referentes a lo que se puede considerar sectores secundario o terciario eran primitivos trabajos derivados de la agricultura o la ganaderia, por ejemplo los del esparto, que realizaba dentro de la alhóndiga en la que estuvo encerrado primeramente en Guadix el ya citado Rodrigo de Siete Iglesias o el almocadén de Matrera, Ramiro, que también trabajó el esparto en Ronda durante diez 
años con la obligación, además, de entregar diariamente a su señor dos dineros de plata que no estaban a su alcance, por lo que durante esos diez años recibió cuarenta azotes diarios y le fueron extraídos doce dientes [47].

El sector terciario está representado por los cautivos que desempeñaron trabajos en el servicio doméstico de sus amos, en actividades tan prolongadas e insufribles como calentar el baño durante doce años en un local cerrado en el que estaba la caldera del agua, un auténtico horno en el que Esteban de Matrera permaneció en Algeciras ese tiempo atenazado por los hierros y del que solamente salió con otros dos cautivos cuando se produjo el milagro [35].

\section{La venta en el mercado de esclavos}

El segundo de los objetivos básicos de la cautividad, además del trabajo, era la venta de estos cristianos a mercaderes y compañías de comercio mediterráneas en las que el reino granadino estaba plenamente inmerso, y a este respecto «...aucun livre ne nous trace un tableau plus saisissant de la misérable condition des esclaves chrétiens pendant le cours du XIII ' siècle»" ${ }^{28}$. La importancia que las racias de frontera tenían en el aprovisionamiento de esclavos, tanto para Granada como para Castilla ${ }^{29}$, resultan evidentes en el texto de Pedro Marín; no solamente los cautivos procedían de acciones fronterizas de este tipo, sino que en su venta actuaba, potenciándola o no, la existencia de las treguas, que en el caso de Gonzalo de Soria y sus compañeros fue determinante de que no se les vendiese en Málaga, porque en 1282 las treguas con Castilla impedían la propia realización de acciones de frontera de este tipo y, sin embargo, el mismo arráez de Málaga indujo a los dos almocadenes que los habían capturado a «...que los catiuos que los leuassen a vender a Algecira, que non era en la tregua...» [53].

Localización de las ventas. - Los milagros recogen la venta de más de 50 cautivos castellanos, en las condiciones materiales más diversas; como tónica general Torres Fontes consideró que «...su valor está siempre en relación con el número de que se dispone, aunque la continuada afluencia a los mercados impide que alcancen altos precios...»; el número, en su opinión, fue muy variable, desde varios miles en circunstancias excepcionales a unos pocos

${ }^{28}$ M. FÉROTIN, Histoire de l'Abbaye de Silos... p. 240.

${ }^{29} \mathrm{CH}$. VerLINDEN, L'esclavage dans l'Europe Médiévale I. Péninsule Ibérique-France, Brujas, 1955 y L'esclavage dans la Péninsule Ibérique au XIV siècle, "Anuario de Estudios Medievales» 7, 1971. J. HEERS, Esclavos y sirvientes en las sociedades mediterráneas durante la Edad Media, Edicions Alfons El Magnànim, Institució Valenciana d'Estudis i Investigació, 1989. 
conseguidos en las acciones fronterizas de cada dia ${ }^{30}$, de modo que los casos documentados de Pedro Marín pueden considerarse como un muestreo de esas ventas, todas ellas localizadas de modo muy concreto:

a) Plazas y fortalezas fronterizas donde se hacían unas primeras ventas 0 adjudicaciones a jefes zenetes y granadinos que se erigían, así, en los primeros beneficiarios de las razias a través de las cuales se abastecía el mercado granadino, en reciprocidad a un fenómeno similar que tenía lugar al otro lado de la frontera. Estas plazas-mercado eran de este a oeste, tal como se desprende del texto de Pedro Marín, en la frontera murciana, Vélez-Blanco en primera línea y Purchena más al interior; en la frontera de Jaén, Alicún y Guadix y Baza en primer y segundo término respectivamente; en el sector fronterizo central Rute, desde donde se destribuían a Granada y Málaga y en la parte occidental la gran plaza de Ronda.

b) Granada, como capital del reino y centro geográfico equidistante de la frontera territorial y del mar, centro de consumo y al mismo tiempo centro de redistribución.

c) Los puertos granadinos y las ciudades muy próximas a las costa, a través de las que estos esclavos eran vendidos o revendidos a mercados africanos o italianos generalmente: Vera, ya muy valorada por Torres Fontes respecto a la frontera murciana ${ }^{31}$, Almería, Málaga y Algeciras eran esas plataformas de exportación.

d) Mercados africanos como Arcila o Salé a los que se llegaba unas veces directamente y, en otras ocasiones, a través de Ceuta como eslabón intermedio.

Valor de mercado. - Analizados los precios alcanzados que trasmite Pedro Marín, se deducen una serie de factores reguladores del mercado granadino de esclavos en la segunda mitad del siglo XIII:

a) La edad y el sexo fueron las coordenadas de valoración más generalizadas, tal como ya ha apuntado González Jimenéz en el caso de los andaluces ${ }^{32}$, que se hacían resaltar a la hora de la venta con una presencia física aceptable: «...leuaronlos al banno por que ualiessen mas dineros...» [70]. De su mayor o menor juventud dependían tanto la capacidad de trabajar como su duración e incluso la posibilidad de obtener una descendencia de esclavos, que en el caso de las mujeres se veía sobrevalorada.

${ }^{30} \mathrm{~J}$. TORRES FONTES, La cautividad de la frontera granadina... Sobre la cabalgada, M. MARTINEZ MARTíNEZ, La cabalgada: un medio de vida en la frontera murciano-granadina (siglo XIII), «Miscelánea Medieval Murciana», XIII, Universidad de Murcia, 1986.

31 J. TORRES FONTES, Repartimiento de Lorca, p. XIX.

${ }^{32}$ M. GONZÁLEZ JiMÉNEZ, Esclavos andaluces... p. 334. 
Ramón y Lorenzo, vecinos ambos de Mula, fueron capturados por Ochaviello cuando volvían a su pueblo procedentes de Lorca; fueron conducidos a Purchena y allí vendidos por 20 doblas el primero y 9 el segundo, sin que existan entre ellos más diferencias que las estrictamente derivadas del estado corporal de cada uno de ellos y, además, se da la circunstancia de que al mismo tiempo se vendió una mula que llevaban por el precio de 16 doblas [41], lo que demuestra el gran valor de una buena bestia de carga y, por otro lado, la mísera condición a que se veían reducidos estos hombres, menos válidos en el caso de Lorenzo que una simple mula.

Entre los tres segadores sevillanos vendidos en Algeciras tras su captura en pleno mes de agosto, cuando se dedicaban a la recolección del cereal en Alcalá de Guadaira, uno de ellos llamado Juan Martínez valió 12,5 doblas y, sin embargo, García de la Torre y Tomás Pérez solamente alcanzaron las 5,5 y 5 doblas, respectivamente [54], porque serían más viejos o menos sanos que su compañero.

El mayor valor de las mujeres es una constante en la obra de Pedro Marín, que resulta muy patente en la venta de los hermanos de Lorca Rodrigo y Teresa, que fueron apresados cuando estaban vendimiando y llevados a Vélez Blanco, donde en almoneda Rodrigo fue adjudicado por 5 doblas y Teresa por 10 [49]. Las tareas agrícolas eran una situación muy frecuente de captura en el caso de las mujeres: escardadoras eran, Mary Aparicio y dos vecinas más de Córdoba capturadas en marzo de 1284 y vendidas, la primera, por 14 doblas en Málaga y vuelta a vender por su primer amo a las tres semanas en la misma ciudad por 19 doblas [50], con un considerable margen de beneficio; segadoras las siete mujeres vecinas de Córdoba que fueron a parar tras su captura al Portal de Jerez, donde Mary Pérez fue vendida por 17,5 doblas [79]. Cuando solamente los hombres de manera excepcional superaban el valor de las 10 ó 12 doblas, estos precios son indicativos del alto valor monetario que podía alcanzar la esclavitud femenina y los beneficios tan considerables que llegaban a obtenerse con ellas.

b) El status de origen del cautivo. Los precios más altos los alcanzaban en primer lugar los individuos pertenecientes a un status medio o alto de la población en las ciudades cristianas próximas a la frontera. La mayor parte de los más altos valores alcanzados se pagaron en doblas de oro y de todos ellos el que alcanzó un más alto precio fue «don Miguel de Cetina», vecino de la villa de Aguilar, que era señorío de don Gonzalo Yáñez; su caso quedó doblemente documentado, en su propia narración según la cual fue vendido en Málaga por 18,5 doblas [72], y en la de su convecino y compañero de desgracia, Benito de Aguilar, que le atribuye una venta de 19 doblas, mientras que por él solamente se pagaron 9 [77].

Sesenta reales de plata, unas 20 doblas, valió el almocadén de Matrera, 
Ramiro, mientras que los quince peones que con él fueron cautivados, como consecuencia de la derrota de Écija de 1285 , se vendieron cada uno por la cuarta parte de este valor en el mercado de Ronda [47]. En tres ventas sucesivas se vio inmerso el también almocadén Martín Domínguez de Aranda, las tres en Ronda, y en ellas pasó de valer 13 doblas en la primera a las 15 de la segunda y las 23 de la tercera, en un muy corto periodo de tiempo [44], porque se trataba de un individuo que debía de reunir todas las circunstancias positivas de máxima valoración y resultaba codiciable.

c) Diferencias económicas comarcales se desprenden de los datos documentales encuadrados en su situación geográfica. El reino granadino queda dividido en cuatro áreas claramente establecidas, en las que tenían lugar de forma dominante los desplazamientos de los esclavos, con interferencias tangenciales de unas a otras.

Estas áreas eran la oriental, con puntos extremos en Vélez Blanco y el puerto de Almería, que limitaba con la frontera murciana; la central continental, que abarcaba la frontera de Jaén y parte de la de Córdoba y tenía como centro de gravedad la ciudad de Granada; la central mediterránea, que por el norte era fronteriza con los reinos de Córdoba y Sevilla y estaba abocada al puerto de Málaga; y por último la occidental sevillano-gaditana, que desde Pruna al norte a Tarifa al sur, incluía la estratégica bahía de Algeciras con su puerto. Entre unas y otras se aprecian unas diferencias de matización en los precios pagados por los cautivos que queda distribuidas así:

\section{Precios en doblas}

Vélez Blanco-Purchena-Vera-Alme-

$\begin{array}{ccc}\text { Máximo } & \text { Mínimo } & \text { Media } \\ 20 & 3,5 & 9,5 \\ 12 & 2,5 & 7,5 \\ 19 & 4 & 11,5 \\ 20 & 4 & 10\end{array}$

La nota dominante es la valoración inferior de los cautivos en el hinterland granadino, por causas que parecen apuntar a la diferencia entre un mercado regional, aunque sea el que tenía por centro la corte y la administración del reino, y lo que parece perfilado como áreas controladas por los tres puertos más importantes del reino nazarita, que estaban conectados con el tráfico a gran escala.

Un buen ejemplo de este tráfico internacional de esclavos lo proporciona el itinerario recorrido con un sinfín de peripecias por el buhonero Juan, vecino de Isso en la frontera murciana, que fue cautivado en las proximidades de 
Alcantarilla por el almocadén de Vera y trasladado a Vélez Blanco en 1284 [55]; a los cinco días de su captura fue conducido a Almería y allí vendido por 5,5 doblas a un mercader de Ceuta, ciudad en la que estuvo solamente nueve días, al cabo de los cuales lo compró por el mismo precio otro mercader que lo condujo a Salé, importante plaza situada al norte de la actual Rabat, que apenas pudo mantenerse tres meses en poder de Castilla, en 1260, tras la conquista por la escuadra que dirigía Juan García de Villamayor.

Ya en Salé, entre miércoles y domingo de una misma semana fue vendido cinco veces consecutivas a otros tantos compradores, el último de los cuales pagó por él 8 doblas para trasladarlo durante cuatro días de viaje a lo que el cautivo denominó «Las Ferreiras» en los Montes Claros, haciendo referencia con esta gráfica denominación a alguna comarca del Rif donde la explotación de minerales férricos es muy antigua. Estuvo allí seis semanas, hasta que en noviembre de ese año empezó a tener las apariciones de Santo Domingo y huyó por parajes costeros hasta llegar al puerto de Safí, situado al sur de la actual Casablanca, donde entró en contacto con una flota de cinco naves de Bayona y otros lugares de Gascuña, cuyos marinos se prestaron a llevarlo con ellos.

Al cabo de cinco semanas de accidentada navegación, bordearon todo el Atlántico de la Península Ibérica, pasando por Finisterre, y llegó al puerto de Ambés, punto de confluencia del Garona y del Dordoña en la Gironda; en Ambés desembarcaron y el pobre buhonero, acostumbrado a trotar en tierra firme, no aceptó la invitación de los marinos que quisieron llevarlo con ellos en un nuevo viaje hasta Sevilla para que desde allí regresara por tierra a su pueblo: "dixoles que muy escarmentado era de la mar, et rogoles que les non pesasse que queria uenir por terreno...», pero fue un viaje relativamente por tierra, porque se embarcó de nuevo, aunque esta vez navegó por ríos: desde Ambés subió aguas arriba del Garona y su afluente el Lot hasta llegar al último punto donde la navegación fluvial era posible, al pie de los montes de Aubrac en Auvernia, y todo ello sin salir de los territorios de soberanía inglesa en el suroeste y centro de Francia.

Desde allí a pie, cruzando Borgoña, llegó a Lombardía, que el buhonero de Isso creía que pertenecía a la soberanía del rey de Francia; algo de verdad había en ello por el control de buena parte de las ciudades italianas del norte, ejercido por Carlos de Anjou de forma clara desde que en 1268 fuera ejecutado Conradino de Sicilia y él se convirtió en el nuevo rey de la isla; el papel de Milán fue decisivo en su triunfo ${ }^{33}$, que dos años antes de que tuviera lugar la huida de este cautivo se manifestó de forma brutal a través de las llamadas Vísperas Sicilianas.

${ }^{3}$ S. RUNCIMÁN, Visperas sicilianas. Una bistoria del mundo mediterráneo a fines del siglo XIII, Alianza Editorial, 1979, p. 102. 
A partir de Lombardía se dirigió hacia el norte; en Picardía debió de estar muy poco tiempo, porque le aconsejaron que la abandonase pronto debido a que era tierra enemiga de los españoles y su vida peligraba. En este caso el buhonero vivía las consecuencias del enfrentamiento político y diplomático de Felipe III de Francia con Alfonso X, por su ayuda a los Infantes de la Cerda, hijos de su hermana doña Blanca, y utiliza el concepto de españoles en un periodo de la historia en el que la comunicación e influencia recíproca entre Castilla y Aragón fueron un factor definitivo de la vida social de los reinos durante la vida de Jaime I y Alfonso X.

Desde Picardía pasó a la tierra más amiga de Flandes y allí embarcó en el puerto de Brujas en una nave de Castro Urdiales que lo trajo a este puerto de la marina castellana a través de las costas de Bretaña, donde estuvieron seis semanas anclados esperando que las tempestades les permitieran continuar. Ya en Castro Urdiales, por la costa se dirigió a Compostela como escala previa de agradecimiento antes de su llegada final a Silos, con los hierros de su cautividad, el sábado 18 de mayo de 1285, día de la Trinidad.

No eran solamente los hispanos próximos a la frontera granadina los que sufrían la cautividad de Granada o los que eran vendidos en Africa; además de castellanos y aragoneses, algunos extranjeros quedan registrados en el texto de Pedro Marín como víctimas de estas circunstancias históricas. Los que más riesgo corrieron fueron los genoveses y otros italianos que empezaban a utilizar insistentemente la ruta del estrecho rumbo al puerto de Sevilla; en 1286, sicilianos de Mesina fueron cautivados en Almería y desposeídos de la nave y todo lo que en ella transportaban, sin que las gestiones de los frailes de Santa Eulalia de Barcelona por conseguir su libertad a cambio del pago de 150 doblas de oro y la promesa de hacer pleito homenaje al rey de Granada dieran resultado positivo [85]; al cabo de dos años de cautividad pudieron escapar en un barco genovés que los llevó a Alicante, desde donde volvieron seis a su tierra, mientras que Simón de Montfalcón y otro compañero fueron a Silos a agradecer a Santo Domingo su intervención.

\section{De LOS LlaNOS MARTíNEZ CARRILlO Universidad de Murcia}




\section{APÉNDICE DOCUMENTAL}

Real Academia de la Historia, códice H-18, folio 18, relato núm. 92.

\section{Como libro las oveias del monasterio}

Era de mill et CCC et XXII annos, aviendo guerras en la frontera, venieron grand pieça de caualleros ginetes con grand poder a correr a Baeça et a su termino et obieron a leuar de termino de Baeça çient mill oueias. Et entre aquellas oueias leuaron de Santo Domingo Silos CC et sesenta oveias, et ninguno de los de la villa non oso sallir a los moros por la grand conpanna que eran.

Et abiendo passado el ganado, allende de todas las vinnas de Baeça, et vieron venir vn can mastin muy grand et muy preto, de partes de Orrente, et metiose entre las oueias et partiolas bien quatro partes, et aparto las CC et LX oveias que eran de Santo Domingo et mordiendolas acoxolas todas ante si et aduxolas a villa de Baeça.

E esto beyendo los caualleros et clerigos et muchos onmes et muchas muchas (sic) mugeres que estauan en las torres et en los adarues de la çerca de la villa, et maguer vieron los ginetes que el can leaua aquellas oveias acogidas ante si, echaron en pos el con so causallos et so roçines et so yeguas et nol podieron alcançar nin façerle ningun mal al can nin a las oveias; et los ginetes con las açagayas et las espadas sacadas de las vaynas corrieron en pos de las oveias et tal fue la birtud de Dios et de Santo Domingo que nin mataron oveia nin ferieron a ninguna.

Quando esto vieron los de la villa, que las oveias et el can venien tan cerca, abrieron la puerta que diçen de Ubeda et acogieron las oveias dentro en la villa, et al can iamas nunqual vieron nin sopieron ende parte nin mandado.

Et esto fue famado por Baeça et por Ubeda et por Iahen et por toda la frontera, et todos quantos lo oyeron esto vieron que lo façia la virtud de Dios et de sennor Santo Domingo.

Et esto conto en la claustra del monesterio de Santo Domingo de Sillos Ruy Perez, vn cauallero de Baeça, lunes otro dia de la dominica de Letare Ierusalem al tiempo de visperas ante de la missa mayor, ante el abad don Iohan et ante Pero Marin et ante otros muchos monges del monesterio; et dixo que lo el viera con su oios, estando en Baeça, ansi le guiasse Dios et Santo Domingo.

Et esto fue dicho en la era de mill et CCC et XXXI anno. 


\section{RÉSUMÉ}

Le texte est une étude comparative des trois seuls manuscrits conservés, qui contiennent le texte intégral ou partiel des «Miraculos romançados» de Pedro Marín; il contient une analyse du paysage végétal, des activités économiques et du marché des esclaves dans le Règne de Granada et utilise, comme source, le texte des «Miraculos» ainsi qu'un appendice documentaire complémentaire.

\section{SUMMARY}

The topic of this article is the comparative study of the three existing manuscripts that contain the whole text -or part of it - of the "Miraculos romançados» by Pedro Marín. We also pay attention to the analysis of the vegetal landscape, the economic activities and the slave market in the reign of Granada. We used the text of the "Miraculos» and the complementary documental appendix as sources. 


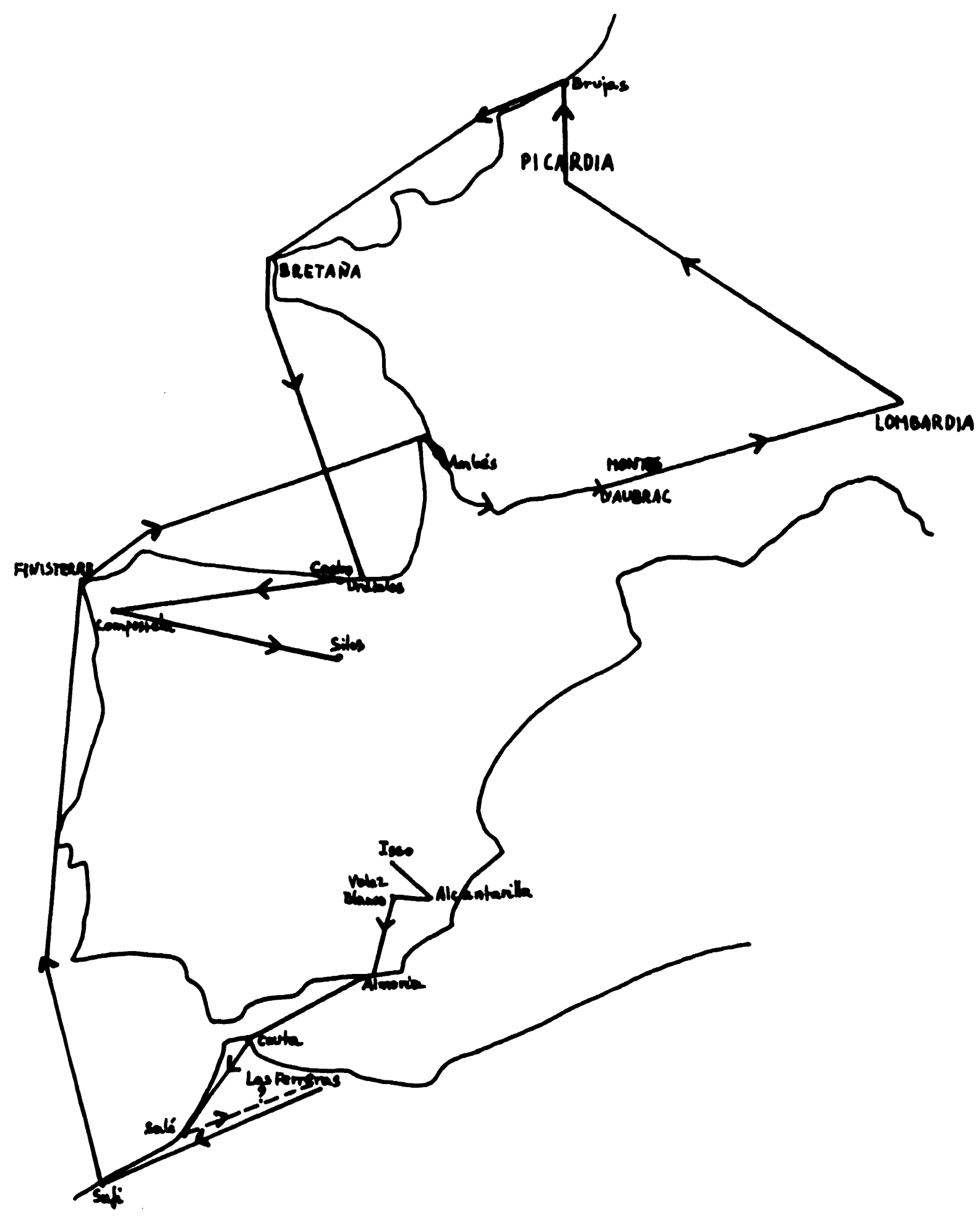

ITINERARIO SEGUIDO POR EL BUHONERO JUAN [55] A PARTIR DE SU CAUTIVIDAD LiN 1284. 